\title{
探析混凝土结构检测方法
}

何昕

齐齐哈尔市质量技术监督检验检测中心

DOI: 10.18686/bd.v1i9.823

[摘 要] 本文作者主要以混凝土结构实体检测项目为主, 分析了混凝土结构实体检测中的抽样原则, 探讨了结构实体的 检测方法。

[关键词] 混凝土; 结构检测

混凝土混凝土强度的检测是建筑结构检测的一个重要 组成部分, 混凝土混凝土强度的检测方法可分为非破损法 和半破损法，相对非破损检测方法和其它半破损检测方法 而言, 钻芯法由于具有不受混凝土龄期限值、测试结果误差 范围小、直观、能真实地反映混凝土强度等诸多优点, 因而 在实际工程中得到了广泛的应用。采用钻芯法获得的混凝 土推定强度, 更是对混凝土结构、构件质量进行评定、验收, 以及有关部门做出对工程实物是否需要加固处理和如何进 行加固处理的一个主要依据。所用的检测仪器必须通过计 量检定, 检测操作应符合相应规程规定。所检测数据和结论 应真实、可靠、有效, 做到公平、公证、公开, 才能供建筑结构 工程质量评价、设计复核验算以及建筑结构性能鉴定等采 用。

\section{1 混凝土抗压强度实体结构检测}

1.1 混凝土抗压强度实体结构检测的原因

1.1.1 当未能按照《混凝土结构工程施工质量验收规 范》GB50204 要求留置试件或对其结果有怀疑时;

1.1.2 当个别构件表面存在质量缺陷 (如蜂窝、麻面、露 筋、裂缝等), 对该构件是否达到设计所要求的强度等级产 生怀疑时;

1.1.3 材料、施工或养护不良而发生混凝土质量问题 时;

1.1.4 混凝土遭受冻害、火灾、化学侵蚀或其它损害时;

1.1.5 需检测经多年使用的建筑结构或构筑物中混凝 土强度而进行的混凝土检测;

1.1.6 建筑工程混凝土结构现场实体质量监督抽检。

1.2 实体检测方法

混凝土抗压强度的实体检测方法, 根据国家现行规范、 标准可采用回弹法、超声回弹综合法、后装拔出法、钻芯法、 钻芯修正法等方法进行检测。

\section{3 实体检测}

混凝土抗压强度实体检测, 根据工程实际情况确定, 一 般采用钻芯法进行检测, 因它能较准确的反映出混凝土结 构实体的真实强度, 是在相应分项工程验收合格、过程控制 使质量得到保证的基础上进行的一项验证性检查，检验实 体混凝土强度是否满足设计要求, 从而保证结构安全。

\section{2 混凝土抗压强度钻芯法检测}

2.1 构件检测抽样应符合下列规定

2.1.1 混凝土强度等级相同;

2.1.2 原材料.配合比.成型工艺、养护条件基本一致和 龄期相近;

2.1.3 构件类别相同;

2.1.4 所选构件具有代表性。

2.2 使用标准芯样试件

抗压试验的芯样试件直径宜使用标准芯样试件, 其公 称直径不宜小于粗骨料最大粒径的 3 倍; 也可采用小直径 芯样试件, 但其公称直径不应小于 $70 \mathrm{~mm}$ 且不得小于骨料 最大粒径的 2 倍。但在实际工程检测中, 应要根据粗骨料粒 径和结构配筋率选取最合适钻芯直径, 提高了芯样成效质 量与构件实际情况相近, 有利于芯样试件的数据更真实、更 准确、更能反映工程实际质量情况,发现问题。

2.3 芯样宜在结构或构件的下列部位钻取

2.3.1 结构或构件受力较小的部位, 在实际操作过程 中, 根据结构力学知识, 选择受力较小的构件, 确定弯矩最 少处,约柱的中部、梁的跨度 $1 / 3$ 处;

2.3.2 混凝土强度质量具有代表性的部位, 混凝土是从 下到上进行浇捣的, 振捣后, 下半部石子则偏多而上半部则 偏少,一般说来下半部的混凝土强度要高于上半部;

2.3.3 便于安放和操作钻芯机的部位, 钻芯机安放最好 在距离工作面 $1.5 \mathrm{~m}$ 以下,便于安全操作;

2.3.4 避开主筋、预埋件和管线的位置, 并尽量避开其 他钢筋, 当结构配筋率比较高, 可采用 $75 \mathrm{~mm}$ 内径钻头钻取 芯样来作抗压试验。

2.4 安放钻芯机的就位时应注意以下方面

2.4.1 安放钻芯机底座时,最好使整个底座与构件表面 完全贴紧后才拧紧膨胀螺丝, 然后调整底座的四个螺丝钉, 使底座牢固贴紧构件表面, 最后才能开始钻芯, 否则钻出来 的芯样会出现“香蕉型”或 “竹节型”等缺陷, 造成混凝土检 测强度与实际强度偏差较大, 影响对结构作出真实评价, 导 致出现误判。

2.4.2 如要安放钻芯机的底座在已批挡乳胶漆层上或 瓷砖上时, 底座紧贴的位置附近应不要弄湿, 否则底座与构 
件接触面处摩擦力减少, 紧固后的底座会在钻芯机高速旋 转过程中会出现滑移, 难以钻取芯样, 或芯样出现喇叭口变 形缺陷, 影响芯样真实抗压强度。

2.5 钻芯机操作过程应注意以下方面

2.5.1 开始钻芯, 推进进刀杆使钻头慢慢接触混凝土表 面, 防止钻头过快局部碰撞构件表面, 导致钻头损坏, 轻压 进刀杆前进钻人约 $5 \mathrm{~mm}$ 深, 保持轻微力道操作进入, 钻芯 过程必须确保供水冷却钻头。

2.5.2 钻芯时要控制好冷却水的流量, 要达到一定流 量, 最宜为 $3 \sim 5 \mathrm{~L} / \mathrm{min}$, 才能排除混凝土碎屑, 减少摩擦, 进 钻顺畅; 当冷却水流量不足时, 不要强行进钻太快, 要适当 减慢, 往反进退刀杆, 否则混凝土碎屑会变稠, 粘住钻头, 难 以进钻,甚至卡机, 损坏钻机。

\section{6 芯样应注意}

样取出时应利用一字螺丝刀沿着钻缝插人, 螺丝刀直 径不宜太大, 宜稍大于钻头嘴壁厚即可, 用锤子沿同一轴线 敲击螺丝刀尾部, 使其缓缓进人, 达到芯样尾部断裂。注意 螺丝刀进人钻缝内的长度要尽可能的深, 如达不到一定深 度, 芯样可能在中部断开, 达不到芯样加工的有效长度。

2.7 芯样试件应符合下列要求

2.7 .1 标准芯样试件, 每个试件内最多允许有 2 根直径 小于 $10 \mathrm{~mm}$ 的钢筋;

2.7.2 公称直径小于 $100 \mathrm{~mm}$ 的芯样试件, 每个试件内 最多只允许有一根直径小于 $10 \mathrm{~mm}$ 的钢筋;

2.7.3 芯样内的钢筋应与芯样试件的轴线基本垂直并 离开端面 $10 \mathrm{~mm}$ 以上。

2.8 芯样应进行端面处理

锯切后的芯样应进行端面处理: 宜采取在磨平机上磨 平处理, 但应保证芯样试件尺寸在规范规定的高径比范围 内。当端面存在局部残缺时, 可用采用水泥净浆补平, 待水 泥净浆达到一定强度后, 再在磨平机上磨平。

2.9 芯样试件的几何尺寸测量

芯样试件的尺寸对混凝土抗压强度存在影响, 在试验 前一定对其几何尺寸测量。

2.9.1 芯样直径用游标卡尺测量芯样中部, 在相互垂直 的两个位置上, 取其二次测量的算术平均值, 精确至 $0.5 \mathrm{~mm}$;

2.9.2 芯样高度用游标卡尺进行测量, 在芯样端面上旋 转 90 度测量二次, 取其二次测量的算术平均值, 精确至 $1 \mathrm{~mm}$;

2.9.3 垂直度用游标量角器测量两个端面与母线的夹 角,精确至 $0.1^{\circ}$;
2.9.4 平整度用钢板尺或角尺紧靠在芯样端面上,一面 转动钢板尺, 一面用塞尺测量与芯样端面之间的缝隙。

2.10 芯样试件尺寸偏差及外观质量

芯样试件尺寸偏差及外观质量应符合下列规定, 相应 的测试数据才有效。

2.10 .1 芯样试件的实际高径比 (H/d) 应不小于要求高 径比的 0.95 或不大于 1.05 ;

2.10.2 沿芯样高度任一直径与平均直径相差不超过 $2 \mathrm{~mm}$;

2.10 .3 芯样端面的不平整度在 $100 \mathrm{~mm}$ 长度内不超过 $0.1 \mathrm{~mm}$;

2.10.4 芯样端面与轴线的不垂直度不超过 20;

2.10 .5 芯样不应有裂缝或有其他较大缺陷。

2.11 脉冲电磁波法

脉冲电磁波法是利用电磁波的运动学原理, 采用无线 发射和有线或无线接收两探头, 发射探头与接受探头分别 置于被测楼板的上下两侧, 当两探头中轴线重合并垂直于 被测楼板, 直接测得的两探头的最小距离, 该距离即为被测 楼板的厚度。该方法测试最小误差为 $2 \mathrm{~mm}$ 。其中脉冲电磁 波法可作为楼面板厚结构实体检测的主要方法, 并辅以少 量的取芯法或钻孔法方法进行对比验证。

\section{3 结束语}

毕竟钻芯法检测是一种局部破损的检测方法, 对构件 结构存在一定的损害, 如取样部位不当, 轻则削弱构件承载 力, 重则损伤主筋或钻断主筋, 且操作过程较为笨重, 费时、 费力。为避免对结构安全造成影响, 提高工作效率, 结构现 场检测仪器及技术的应不断创新、发展, 对工程质量的检 测、处理方面, 具有十分重要意义。随着科学的不断发展, 许 多新材料被工程所应用, 建筑结构设计的不断改进, 迫使测 量仪器小型化、智能化, 测试精度提高, 不断改进操作方法, 使其日趋简单、高效, 以保证现场检测的需要, 适合更复杂、 大面积建筑工程质量的检测。

\section{参考文献:}

[1]张治泰, 李乃平. 关于钻芯法检验结构混凝土强度 问题[J].工程质量, 2010,(06).

[2]谢建军.建筑结构检测试验鉴定研究 [J]. 大众科技, 2012,(04).

[3]梅新忠, 王振德, 孙福印.混凝土现浇板厚度测试方 法探讨[J].工程质量.2004(09 副刊): 62-63

[4]梅新忠、王振德、孙福印、混凝土结构实体钢筋无损 检测方法技术探讨[J].工程质量.2004(09副刊): 63-64 